Fecha de recepción: mayo 2014 Fecha de aceptación: mayo 2015 Versión final: julio 2016

\section{El Diseño como estrategia de Postponement en la MVM Manufactura del Vestuario de la Moda}

Francisca Dantas Mendes *

\begin{abstract}
Resumen: Esta investigación es el resultado del trabajo del Grupo de Investigación "La moda de la cadena textil", según el registro del Directorio de los Grupos de Investigación CNPQ. El producto de moda tiene características específicas ofrecidas por el diseño quien otorga, a través de la creación, un estilo cuya finalidad es satisfacer el deseo de un determinado público objetivo. Hoy en día la moda puede ser considerada democrática, ya que el público consumidor es el protagonista en la toma de decisiones sobre lo que debe ser producido. En cada temporada la moda tiene que presentar una amplia variedad de novedades en sus formas, colores, materiales y texturas, haciendo posible que las marcas que producen prendas de moda lleguen a diferentes públicos objetivos para satisfacer los deseos de los más osados e innovadores, los que siguen la moda y los más conservadores que consumen una moda más moderada. El producto de moda tiene que satisfacer una demanda del mercado que busca productos altamente diversificados y com un alto nivel de diferenciación. Es importante que al final del proceso de producción, pocas piezas tengan la misma apariencia. El Postponement es un término que define la decisión de posponer las etapas finales del proceso de producción por varias razones. Puede ser utilizado en la FRM como una estrategia para aumentar la tasa de diferenciación de los productos, tal como determina la demanda del consumidor de moda.
\end{abstract}

Palabras clave: diferenciación - estrategia - Moda - Postponement - ropa - tratamiento.

[Resúmenes en inglés y portugués en las páginas 327-328]

${ }^{(*)}$ Actualmente es profesora doctora de la Escuela de Artes, Ciencias y Humanidades de la Universidad de San Pablo, en el Curso de Textil y Moda. Esta graduada en el Curso Superior de Moda por la Universidad Anhembi Morumbi (1994), maestría en Ingeniería de Producción por la Universidad Paulista (2006) y doctorado en Ingeniería de Producción por la Universidad Paulista (2010). Tiene experiencia en el Universo del Vestuario de Moda, con énfasis en Administración de Productos de Moda, Modelado y Costura, PCP, actuando principalmente en los siguientes temas: vestuario, moda, textil. Realiza investigación y publicaciones en artículos, congresos y libros y trabaja por una cultura de paz en el Manifiesto 2000, con proyectos de inclusión social. 


\section{Introducción}

El deseo de los consumidores de la ropa de moda es principalmente destacarse y diferenciarse de los demás, aunque manteniendo un sentimiento de pertenencia al grupo que comprende el mismo nicho de consumo y en busca de productos con una misma estética. El producto de moda cuenta con estacionalidad según la temporada clima y la tendencia de la moda en un período determinado. Las principales capitales de la moda, París, Londres, Nueva York, Tokio y otras, presentan en cada nueva temporada, a partir de la creación de los estilistas o los designers de moda, nuevas colecciones prêt-à-porter y piezas de ropa con diseños innovadores para diferentes consumidores.

Para tener éxito en un mercado altamente competitivo como el de la ropa de moda, las marcas o las empresas de moda tienen que establecer algunas estrategias para que, además de la supervivencia de su marca, consigan la consolidación del producto en el mercado de la ropa de moda.

Porter (2004) identificó tres importantes estrategias a seguir por las empresas que buscan una buena competitividad y consolidar su marca y liderazgo en el mercado. Estas son los liderazgos en la diferenciación en los productos, en el costo y en el enfoque. El mercado de producto de moda claramente encuentra apoyo en las tres estrategias de Porter.

El design es uno de los factores de mayor valor agregado en el producto de moda cuando se aplica como una estrategia de aplazamiento, permitiendo la producción de un gran volumen de partes diferenciadas.

\subsection{Metodología}

En esta investigación las fuentes teóricas de la metodología descritas por varios autores, entre ellos Yin (2008), Lakatos y Marconi (2010) y Charoux (2006) son necesarias para determinar un conjunto de acciones que permitan la recogida de informaciones y datos de una o más empresas participantes en un escenario poco documentado y estudiado.

\begin{tabular}{|l|l|}
\hline Descripción & Especificaciones \\
\hline Carácter del estudio & Exploratorio, descriptivo \\
\hline Metodo de enfoque más amlio & Hipotético -deductivo \\
\hline Enfoque & Cualitativo \\
\hline Métodos de Investigación & Estudio de Caso \\
\hline
\end{tabular}

Tabla 1. Resumen de las opciones metodológicas. Fuente. elaboración propia. 
La Tabla 1 presenta una serie de métodos que se utilizarán para la investigación. La elección del método radica en la necesidad de buscar ideas en un tema en particular, describiendo comportamientos o clasificando datos y variables. Las observaciones se hacen en el local y con entrevistas semiestructuradas. El objetivo del investigador es ampliar las teorías y no enumerar frecuencias. Observar, explorar y describir situaciones en las que las preguntas "cómo", "cuándo" y "por qué" sean la base de la investigación con el fin de engendrar características y enlaces de importancia teórica. El estudio del caso es de gran importancia cuando se consideran las particularidades del entorno de la producción. La investigación científica sólo se completa con una visita técnica a una empresa envuelta con el objeto de estudio.

\section{La cadena textil y la moda}

La cadena textil envuelve un gran número de industrias que suministran sus productos como materias primas para otras industrias del sector y también para el consumidor final. Todas estas industrias sufren una mayor o menor influencia del ciclo de la moda.

La figura 1 muestra la red de las industrias y el impacto que en mayor o menor medida, es causado por el ciclo de la moda de acuerdo al producto y la percepción del consumidor final en la venta minorista.

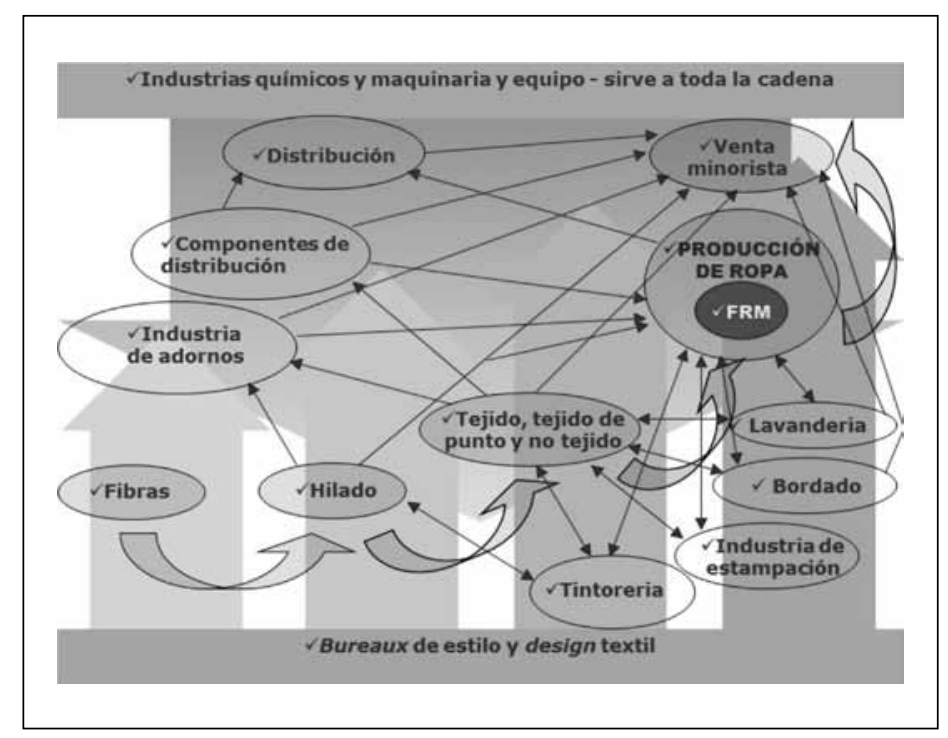

Figura 1. La red de las industrias donde se inserta la FRM. Fuente. Mendes (2010). 
Se observa en la Figura 1 el eje principal que comprende la producción de fibras, hilado, tejido tela plana, tejido de punto y tejidos no tejidos, la producción y finalmente la venta minorista.

El grupo está compuesto por fibras de la agropecuaria (animal, vegetal), de la industria manufacturera (fibras mixtas y minerales) y químicas (fibras sintéticas).

El hilado en Brasil, en su totalidad industrial, suministra hilos al grupo de tejedurías, tejido tela plana, tejido de punto y tejido no tejido. También suministra fuera del eje principal a la industria de adornos y al mercado minorista.

El grupo de tejedurías, tejido de punto y tejido no tejido mantiene relaciones con casi todos los demás actores de la cadena o a través de la entrega directa o por dos vías (flecha de dos puntas), como en los casos de teñido, estampado, bordado y de lavandería.

En el eje principal la industria de la confección recibe el tejido como su principal materia prima. En su interior se encuentra la FRM que se compone de grandes, medianas y micro empresas productoras de ropas en sus diferentes segmentos, destinadas al mercado minorista. Alrededor de ellas hay más industrias de tratamiento, proveedores de servicios y de procesamiento.

Todas las empresas de la cadena textil, de alguna manera, se ven afectadas por el ciclo de la moda. En menor medida, hay impactos en el grupo de las fibras, pero otros sufren constantemente fuerte influencia de los movimientos nacionales y / o internacionales de las tendencias de la moda, en particular el FRM y sus proveedores de servicios.

De acuerdo con Mendes (2010) la cadena textil consiste en un conjunto de pasos consecutivos, a lo largo de los cuales los diversos materiales sufren un cierto tipo de transformación constituyéndose en un producto final y su comercialización. Se trata de una sucesión de operaciones que implica, además de los procesos productivos, servicios funcionalmente integrados que agregan valor al producto final.

El producto de la ropa de moda destinado a los consumidores es muy elaborado y es el resultado de varias fases de investigación que se inician en las tendencias mundiales de la moda, en los nuevos materiales disponibles y en las nuevas formas y volúmenes imaginados. Se produce como consecuencia la creación de productos innovadores, muy diversos en sus formas y en el alto nivel de diferenciación de texturas, colores y estampados.

El resultado de la FRM es un gran número de productos de moda distribuidos en pequeños lotes. Su ciclo de vida es muy corto debido a la demanda de los consumidores por productos innovadores en tiempos cada vez más reducidos.

El diccionario Aurélio define la moda como "el uso, la costumbre o el estilo, generalmente aceptados, variables en el tiempo y que resulta de un gusto particular, idea, capricho y de la interferencia del medio." Souza (1987) define la moda como un término más restringido, reservado a los cambios periódicos en los estilos de vestirse y en otros detalles de adorno personal.

El producto de ropa de la moda se desarrolla a partir de las encuestas sobre las tendencias de la moda y puede ser clasificado entre los productos commodities y diversificados. Los productos commodities tienen una misma forma, sólo que en diferentes colores y estampados (ver Figura 2), mientras que los productos diversificados tienen formas y volúmenes desiguales entre sí, pudiendo todavía ser diferenciados por los colores y los estampados (Figura 3). 


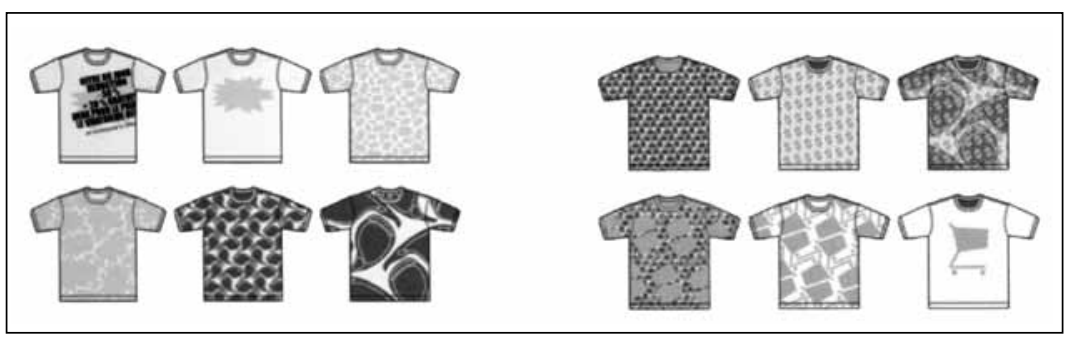

Figura 2. Productos commodities. Fuente. IFM (2005).

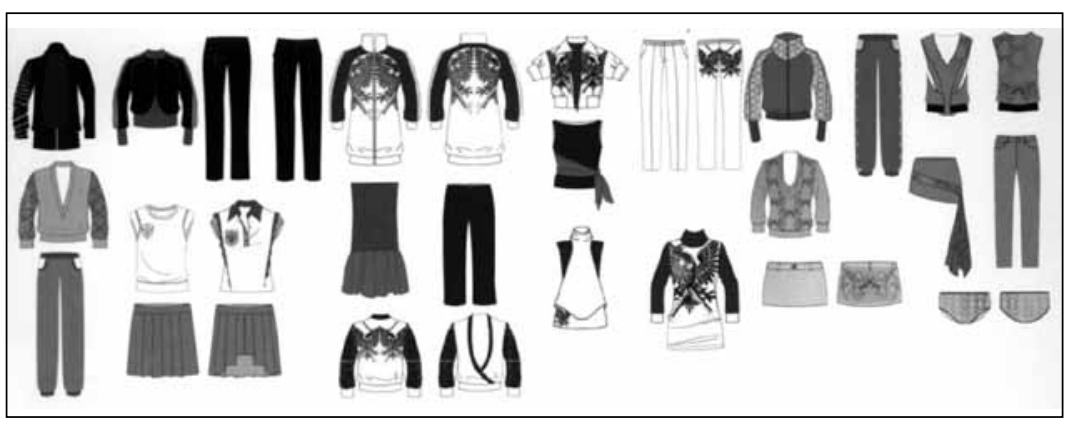

Figura 3. Productos diversificados. Fuente. IFM (2005).

De acuerdo con Mendes (2010), los productos tienden a ser commodities (Figura 2), distinguiéndose por tener una producción de un gran número de piezas a gran escala sólo diferenciados por los colores y los patrones de la tela. Ya presentados en las distintas combinaciones de colección de la moda (Figura 3), tienen características de innovación, formas y volúmenes diferentes y tratan de satisfacer la tendencia de la moda por un cierto período de tiempo (estación clima).

La importancia de la diferenciación del producto de la moda es descrita por Lipovestsky $(1989$, p. 32) “.... no es que la moda no reconozca como igualmente verdaderas las innovaciones, pero ellas son mucho menos frecuentes que la sucesión de pequeños cambios en los detalles. Es la lógica de los cambios menores lo que caracteriza la moda; ...”

Estos pequeños cambios en el aspecto del producto, también son proporcionados por las etapas finales del proceso de producción. A partir de los procesos del teñido y de la impresión, localizada o a lo largo del tejido y de los procesos de lavado que cambian el tono de los colores y la textura de los tejidos; existe en los productos finales un aumento en el número de variedades de piezas y una consecuente reducción en el número de piezas similares, lo que resulta en piezas próximas a ser exclusivas al diferenciarse los productos de la colección. 


\subsection{Fabricación de Ropa de Moda - FRM}

El FRM, insertado en la cadena textil, definida comúnmente como producción de la ropa, en la actualidad va más allá del departamento de costura. En las últimas décadas consiste en una red de empresas con el objetivo de producir ropa con requisitos específicos para un público consumidor determinado. Hacen parte de esta red, empresas que poseen marcas de moda y proveedores de servicios de desarrollo de productos, costuras, tratamientos de estampados, procesos de lavados, distribución y venta minorista. Actualmente existe una venta minorista de la moda que es segmentada a partir del estilo de vida de los consumidores y por productos, de acuerdo con las necesidades específicas de ese cliente y ya lista para la entrega.

Como resultado, el FRM debe seguir las necesidades del mercado que ofrece procesos y servicios para satisfacer esta demanda. Las empresas de moda, aparte de desarrollar nuevos diseños basados en nuevas formas y volúmenes de sus productos, también están desarrollando nuevos visuales a partir de diseños de estampas y de lavandería con la finalidad de satisfacer los deseos de sus consumidores.

Muchas empresas de moda, con el objetivo de desarrollar habilidades específicas, empezaron a subcontratar diferentes etapas de la producción. La mayoría de estas empresas, además de mantener un departamento de desarrollo de productos, tiene en sus instalaciones, un departamento de corte, iniciando la externalización de las etapas de los procesos de costura, tratamiento, teñido, impresión y lavandería. El término subcontratación se utiliza normalmente para designar a la contratación de empresas de servicios para llevar a cabo ciertas etapas del proceso de producción.

La Figura 4 muestra las etapas de desarrollo de productos y la producción de una empresa de FRM.

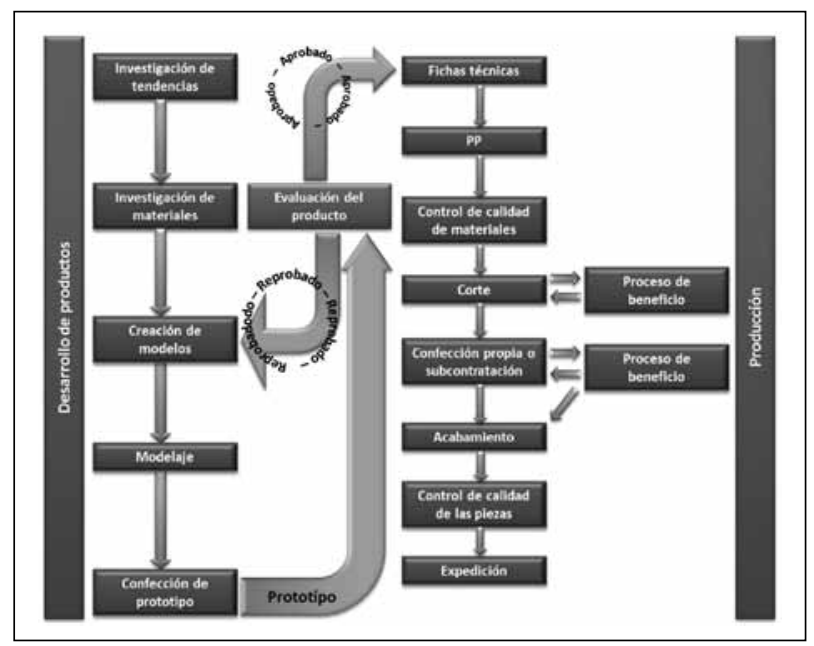

Figura 4. Desarrollo del producto y proceso de producción. Fuente. Mendes (2010). 
Por lo general, el primer paso en el proceso consiste en el desarrollo del producto y se lleva a cabo por las propias empresas, ya que es una zona de importancia estratégica y competitiva, sobre todo porque sólo ellos conocen las características y los deseos de su público consumidor. Esta es la etapa en la que se define el tipo de diferenciación que va a modificar el aspecto final del producto, el que mejor se adapte a la particular creación. Para el proceso de elaboración final, el creador define los diseños que se utilizarán en tintura, estampado, lavanderías y /o empresas de bordado.

\subsection{Tintorerías y procesos de estampación}

Las tintorerías pueden modificar los tejidos a través del teñido con diferentes colores planos. Estos tejidos pueden recibir entonces una estampa a lo largo de la tela modificando completamente sus características visuales.

De acuerdo con Mendes et al (2010), algunas empresas de moda compran un gran lote de tejidos y luego tiñen la cantidad de yardas necesaria para cada color con el fin de aumentar el número de artículos de acuerdo los proyectos de desarrollo del producto.

Las industrias de estampación modifican un gran lote de tejidos a partir de un proceso de transferencia de la imagen situada o a lo largo del tejido. Esta transferencia puede ser ejecutada a partir de diferentes técnicas y puede utilizarse también para rejuvenecer los tejidos que han quedado fuera de moda.

De acuerdo con Andreoni (2008), las impresiones localizadas poseen dimensiones determinadas y pueden aplicarse con diferentes métodos. Como ejemplo de estos métodos tenemos las técnicas de silk screen, esta consiste en la aplicación de pigmentos (producto con coloración) sobre una tela que permite el paso de la masa a través de algunos espacios huecos que poseen las formas de las imágenes que se graban en el tejido y el estampado en caliente, término técnico utilizado para la transferencia de los colores a través de un proceso de fijación por calor.

La estampación que a lo largo de la tela se puede realizar por diferentes técnicas. Según Andreoni (2008), "la impresión con marco" se realiza con marcos aplicados a lo ancho del tejido sucesivamente, utilizando el método de silk screen, donde cada marco transfiere una forma colorida al tejido, siendo que el número de fotogramas varía con la patrón del design. El cilindro de impresión por pantalla trabaja del mismo modo que la técnica de estampación del marco, con la diferencia que los dibujos están en un cilindro que rueda sobre la tela transfiriendo la forma coloreada a lo largo de la tela.

Actualmente la técnica por transferencia térmica a lo largo de la tela es ampliamente utilizada. Este tipo de técnica de acuerdo Andreoni (2008), llamado sublimación de tinta consiste en la existencia de colorantes con las formas y los colores impresos en papel siliconado para sustratos textiles que después se transfieren a la tela por un proceso de termoformado.

Con el desarrollo de la estampación digital surgieron algunas técnicas. El proceso para la impresión digital directa consiste en la transferencia de color por inyección de tinta, de 
colorantes para cualquier superficie de los sustratos textiles. Una impresión láser consiste en la corrosión de las capas de color por medio de un haz láser que puede penetrar en los sustratos textiles para conseguir cada camada de color (Andreoni, 2008).

\subsection{Procesos de lavandería}

Las lavanderías están siendo ampliamente utilizadas por las empresas de moda con el fin de aumentar la diferenciación del producto a través del proceso de lavado. Lo que entra son tejidos, productos fabricados, productos químicos y productos para su distribución. Sus productos son piezas confeccionadas con tratamientos, acabados y artículos diferenciados de moda (Mendes et al, 2010).

Las empresas de lavandería modifican las características del tejido a partir de procesos químicos, físicos y físico químicos. Estos procesos son ampliamente utilizados en el segmento “jeanswear”. Según Lima (2008) el proceso químico altera el tejido o las piezas mediante el lavado con el uso de máquinas de lavar que contienen solamente productos químicos.

Ya los procesos físicos modifican ciertas partes de la pieza con el uso de herramientas (para erosionar el color), molienda (para destruir las fibras) o prensa (para unir partes del tejido formando arrugas). Los procesos físico químicos consisten en poner los productos químicos a lo largo de las piedras en las lavadoras. Este proceso da al producto un aspecto visual diferenciado de acuerdo con el aumento o la disminución de la cantidad de productos químicos o de piedras usadas en el proceso de lavado. Todos estos procesos pueden utilizarse juntos o por separado, de acuerdo al design concebido previamente.

Según Lima (2008), la demanda de lavandería externalizada se consolidó en los años 80 con la expansión de "jeanswear", uno de los segmentos que utiliza más procesos de lavanderías. Tiene como objetivo suavizar, clarear, cambiar el tono del color, el envejecimiento y proporcionar un aspecto de "destruido" o dañados en el "denim". El denim es el tejido utilizado como la principal materia prima para el jeanswear producto.

\subsection{Proceso de bordado}

Las empresas de bordado alteran el aspecto de la tela usando máquinas de bordar que, a partir del movimiento de la aguja aplican líneas de diferentes colores y rellenan las cavidades formando diferentes diseños. Esta técnica se puede utilizar a lo largo del tejido o en bordados localizados.

Según Lima (2008), existen varias técnicas para los diseños de bordados: a) utilizar sólo las líneas (hilos); b) uso de líneas sobre la aplicación de otros tejidos o materiales; c) la aplicación de lentejuelas; d) la ejecución de pequeños agujeros en el tejido, arrematados por líneas con diferentes formas. Todas las formas de los dibujos son previamente concebidos por un diseñador. 


\section{Estrategia de liderazgo del mercado}

Los conceptos de liderazgo en la diferenciación de los productos, del costo y del enfoque defendido por Porter (2004) encuentran significado en el mercado de la moda.

La diferenciación es una de sus características más importantes, ya que se trata de productos cuyos diseños son muy variados por exigencia del público consumidor, ávido de novedad y singularidad. El resultado implica en productos casi exclusivos en lo que se refiere a su aspecto.

La feroz competencia entre las marcas en la industria obliga a las empresas a perseguir la reducción de los costos y a un estricto control de los gastos generales, como una forma de posibilitar las fluctuaciones en sus precios. Hoy en día, en un mercado con posibilidades de producción global, es importante que las empresas gestionen sus costes con el fin de mantener sus precios justos y competitivos. También es necesario promover la producción en masa para conseguir la mayor dispersión posible de los costos fijos. En la fabricación de la ropa de moda, sin embargo, la escala de producción no se caracteriza por ser el principal objetivo, teniendo en cuenta la necesidad de la producción de los productos finales en pequeños lotes.

El liderazgo del enfoque en el caso del mercado de la moda consiste en la organización en la búsqueda de una ventaja competitiva en un segmento o nicho que se ha elegido, con exclusión de los segmentos restantes. La estrategia de enfoque se puede dividir en el enfoque del costo (cuando la organización busca una ventaja de costos en el segmento escogido) y en un enfoque centrado en la diferenciación (cuando la organización busca la diferenciación en su segmento objetivo). La base de esta estrategia es la selección de segmentos específicos del mercado donde la competencia tiene dificultades para cumplir, de manera eficaz, las necesidades de los consumidores. Es fundamental que las empresas conozcan las necesidades e intereses de su público objetivo para poder ofrecer el producto exacto y diferenciado deseado por el cliente.

Por tanto, el liderazgo de enfoque implica en productos destinados a un público específico de consumidores. Este tipo de liderazgo es importante en el mercado de la moda, ya que son variados los estilos de los consumidores con sus exigencias específicas conforme a cada estilo de vida.

\subsection{Estrategia de Postponement}

La estrategia de Postponement permite aplazar, para la última etapa del proceso de fabricación, la diferenciación de productos según las necesidades y la demanda del mercado. La estrategia consiste en promover la producción en masa hasta una determinada etapa de la industrialización.

Van Hoek (1998) destaca los resultados de Postponement para la personalización evaluando que el retraso de las etapas finales de los del proceso de producción resulta en un au- 
mento de la flexibilidad y de la capacidad de respuesta frente a los cambios en la mezcla de la demanda de diferentes segmentos del mercado, además de la reducción de la inversión en stocks. El retraso en la fabricación permite la separación de la personalización de los productos de acuerdo a la demanda del mercado.

El aplazamiento de la producción, llamada por algunos autores como, de hecho, una estrategia competitiva es utilizado principalmente por las empresas para aumentar la agilidad y la flexibilidad del proceso de producción desde el final de la línea, tratando de satisfacer las demandas de un mercado cada vez más volátil por productos con ciclo de vida corto y alto nivel de diferenciación entre los productos de baja predictibilidad de venta (Cunha, 2002).

\subsection{Design}

El design puede entenderse como el acto de diseñar que resulta en una figura o imagen de un producto o algo que pueda representar la expresión de una creación.

Según Denis (1996), el sustantivo design se refiere tanto a la idea de design para planificar, designio, intención, cuanto a la configuración, la disposición, la estructura, y no sólo objetos de fabricación humana, pues es perfectamente aceptable en inglés, mencionar el design como referencia al universo o a una molécula, imágenes apenas idealizadas, no reales. Su origen está en el latín designare, verbo que cubre ambas direcciones, para el designar y el dibujar. Nos damos cuenta de que, desde el punto de vista etimológico, el término ya contiene, en sus orígenes, una ambigüedad, una tensión dinámica entre el aspecto abstracto de concebir, proyectar, asignar y otro concreto de registrar. Para Araújo (1996), el design se puede definir como una actividad de un equipo con la tarea de desarrollar la inspiración, la percepción y la interpretación como sea posible en términos de productos que puedan ser producidos y comercializados complementando los elementos estéticos y funcionales requeridos para el diseño de un producto. El autor concluye: "La tendencia hoy en día va en el sentido de que las empresas utilicen el design con el fin de producir más eficientemente el producto adecuado al precio adecuado para el mercado correcto y en la cantidad correcta."

El uso de la frase "en el universo de la moda" se convirtió una expresión común a mediados del siglo XIX, después de que surgió en Inglaterra y se extendió a los otros países europeos. Un número considerable de trabajadores comenzó a llamarse a sí mismos designers vinculados sobre todo, pero no exclusivamente, a la producción de motivos ornamentales en la industria textil (DENIS, 1996).

Para concebir un design de moda, Jones (2005) sugiere que el diseñador seleccione las mejores ideas y las agrupe en "temas" y luego metódicamente, desarrolle la creación con diseños que puedan modificar sus proporciones y probar las diferentes opciones formas, volúmenes y detalles. El desarrollo del design requiere ilustraciones realizadas con claridad y en las proporciones adecuadas para que los demás puedan entenderlas con facilidad, para expresarlo en el proceso de producción. 


\subsection{El design utilizado en el Postponement}

El design usado en la estrategia de Postponement es también una estrategia de segmentación del producto y también puede ser aplicado en los procesos de lavado, impresión y bordado. Estos designs dan a los productos las características que se encuentran dentro de las últimas tendencias de la moda, tales como la fuente y el tamaño de la fuente, tamaños y tipos de flores, imágenes florales, grafismos étnicos, entre tantos otros patrones.

\subsubsection{Design de lavandería}

Jeanswear es el segmento que más se utiliza de la lavanderia como un proceso de diferenciación de los productos de moda. Los métodos consisten en la aplicación de procesos químicos para cambiar los colores y las piezas de tejido tonos. El tratamiento físico-químico cambia la visual despedazado, y blanqueamiento pregoados en partes definidas de la pieza, la figura 6, dando las características de desgaste excesivo, de acuerdo a los diseños desarrollados anteriormente.

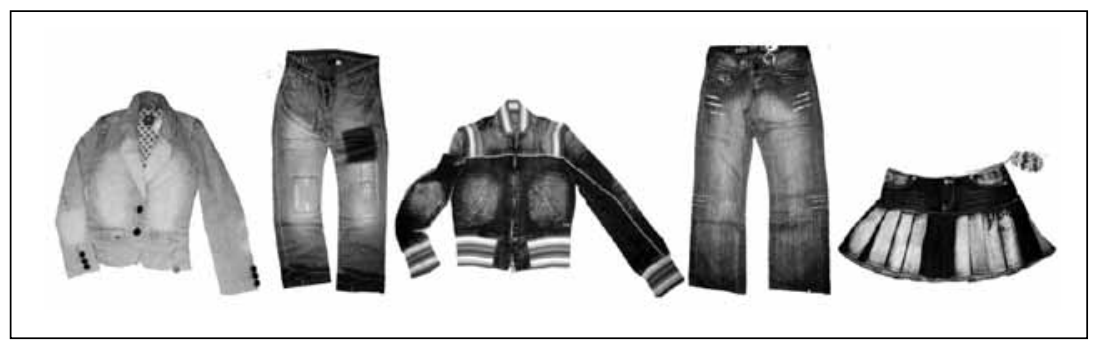

Figura 5. Ejemplos de productos confeccionados en denim. Fuente. Clariant (2007).

La estrategia de Postponement, utilizando el design de lavandería como una forma para diferenciar los productos en pequeños lotes, en la etapa final del proceso de producción, tiene como objetivo satisfacer las necesidades de los diferentes tipos de consumidores.

Un lote de producción a gran escala puede ser modificado por el proceso de lavado utilizado en el design que resulta en una amplia variedad de productos, la Figura 5. Los colores pueden ser alterados por lavado químico. 


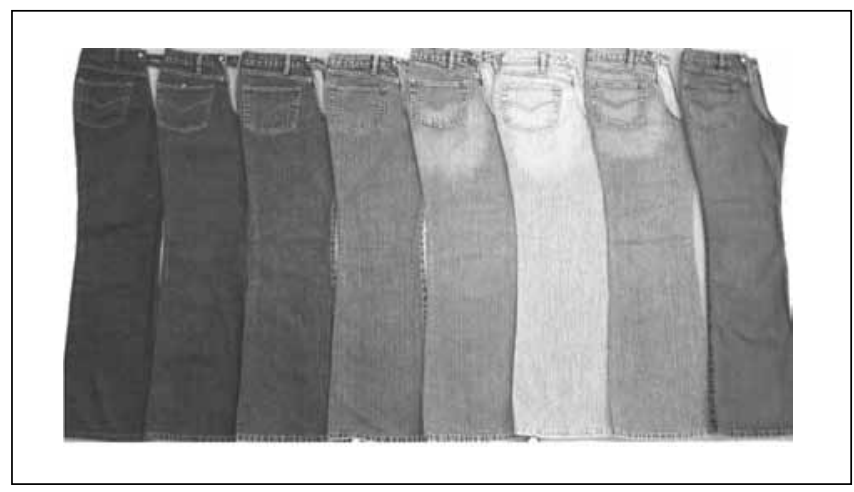

Figura 6. Efectos de la terminación de jeanswear. Fuente. Santista (2005).

Como un segundo paso, después de modificar los colores, los productos pueden ser segmentados de nuevo con el cambio de design a través de procesos físico químicos de lavandería (Figura 6).

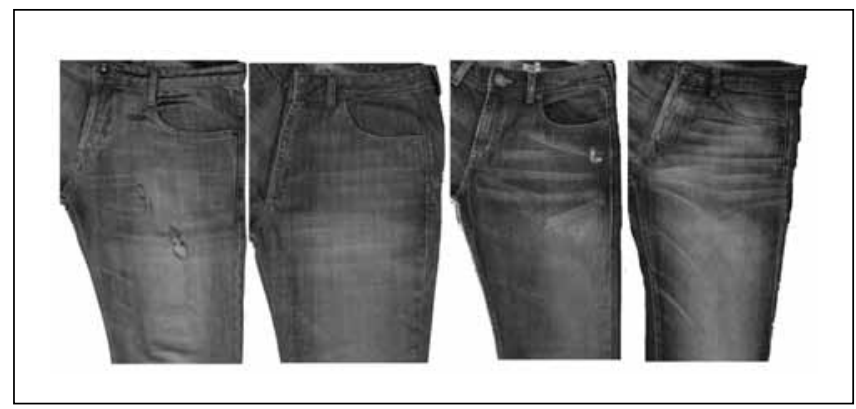

Figura 7. Efectos físico químicos. Fuente. Material de publicidad de Clariant (2007).

\subsubsection{El design de teñido e impresión}

El proceso de teñido permite que a partir de un gran lote de piezas confeccionadas, pequeñas cantidades se sometan a procesos de teñido, cambiando el color de la tela. Según Mendes et al (2010), hay lotes de piezas elaboradas con telas y adornos (líneas, cremalleras, botones) en LT (listo para el teñido), un término que se utiliza para teñir después. Este 
lote debe esperar la definición de las cantidades de los artículos vendidos por color y numeración. Entonces, el lote se tiñe posteriormente de acuerdo a la demanda del cliente. (Figura 8)

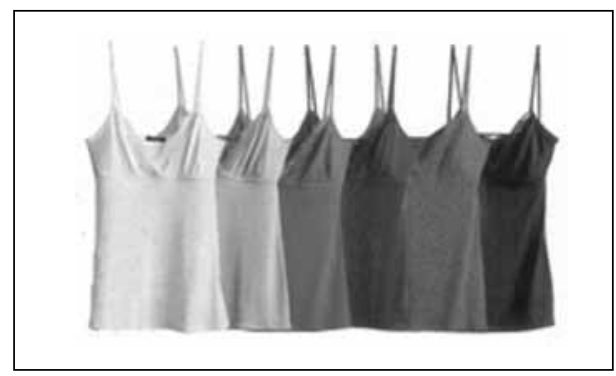

Figura 8. Catálogo de ventas La Redute (2010). Fuente. La Redute.

Un lote de piezas teñidas se puede separar en menor cantidad y recibir el proceso de impresión localizada (Figura 9) con design, dándole un nuevo estilo al producto destinado al público consumidor.

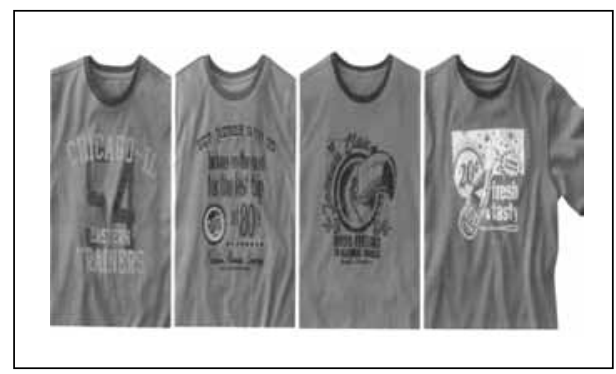

Figura 9. Estampas localizadas. Fuente. Catálogo de ventas La Redute (2010).

\subsubsection{El design de bordado}

Las empresas de moda desarrollan diferentes diseños que se aplican en el proceso de bordado localizado en la pieza en diferentes pequeños lotes (Figura 10). 


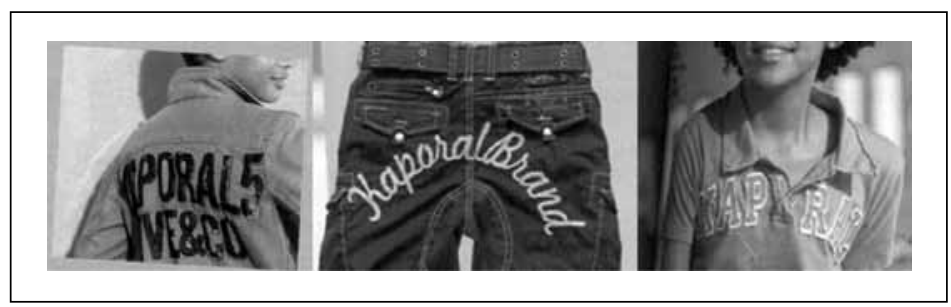

Figura 10. Bordados localizados. Fuente. Catálogo de ventas La Redute (2010).

La estrategia de Postponement utilizando el design en los diferentes tipos de procesamiento tiene el propósito de segmentar y asignarle al producto más estilo de acuerdo con las características deseadas por el usuario final.

\section{Estudio de caso}

Los criterios para la elección de la empresa tuvieron en cuenta algunos aspectos: 1) debería ser una empresa de moda que desarrollase la creación de sus propios productos, 2) que fuese dueña de su propia marca de mercado establecida hace más de 15 años, 3) que estuviese involucrada con todos los engranajes de la moda del medio fashion, 4) que tuviese vínculos con todos los eslabones de la cadena textil, 5) que su producción fuese toda subcontratada en varias facciones, 6) que tuviese procesos de terminación final en sus productos, 7) que tuviese una amplia variedad de productos en su colección.

Estamos hablando de la empresa SLS cuya marca es consagrada en el mercado. Cuenta con una tienda propia y una sala de exposición en la empresa. Hay tiendas en franquicia de su marca en siete capitales de provincias del país. Emplea cerca de 50 empleados directos distribuidos en los departamentos administrativos, de desarrollo de productos, de compras, PCP, de marketing y en la alta dirección. Aproximadamente otros 30 trabajadores tienen funciones indirectas y se distribuyen en los departamentos de ventas.

Para cada colección la empresa desarrolla, en promedio, un mix de 350 productos nuevos distribuidos en aproximadamente 80 diferentes tipos de materias primas que van desde tejidos y géneros de punto. Como una estrategia para aumentar las ventas, la compañía lanzó otra pequeña colección de más de 180 modelos diferentes. Para aumentar el alcance de los artículos, 530, aproximadamente, están siendo distribuidos en diferentes colores, con diferentes diseños y tamaños, que han llegado a una producción total de 55.000 60.000 artículos en cada temporada.

La prioridad competitiva de la SLS es en el estilo, la calidad del producto y la satisfacción del cliente. 
La propuesta consiste en satisfacer una demanda del mercado de productos innovadores considerados de moda y casi exclusivos, razón por la cual posee por colección, un gran número de productos producidos en pequeñas cantidades (según el modelo) y muy diversificados en el modelado estético, los estampados y los tejidos.

La empresa desarrolla dos importantes colecciones de primavera / verano y otoño / invierno, y una intermedia en pleno verano. Crea y produce sus propias colecciones en su departamento de desarrollo de productos en el que mantiene un equipo de estilo, diseñadores y "piloteiras".

Como estrategia competitiva, la producción es totalmente externalizada, lo que permite concentrar todos los esfuerzos en el desarrollo de los productos.

El equipo de desarrollo de productos se compone de diseñadores con sensibilidad para percibir las tendencias de moda más atrevidas. Viajes a Japón, Estados Unidos y Francia se realizan dos veces al año para la investigación y la comprensión de las obras publicadas por los principales diseñadores internacionales.

El uso de la palabra fashion asignado a un producto o a una empresa, o incluso a determinados ámbitos de la moda, confiere un estatus superior y diferenciado. La empresa en cuestión se inserta en este contexto de la moda, una vez que el público consumidor de sus productos (precios por encima de la media del mercado) pertenece a la llamada clase media / alta.

Además de las piezas de sus colecciones, la SLS compra algunos productos únicos, desarrollados y producidos en colaboración con terceras empresas que producen partes de la marca con las mismas características de estilo y calidad de sus productos. En este caso, a los productos se les da la etiqueta de SLS, como es el caso de los pantalones vaqueros y a algunos modelos de suéteres y bolsas de punto, por ejemplo.

Como la producción de la estrategia competitiva es totalmente externalizada, lo que permite concentrar todos sus esfuerzos en el desarrollo de productos.

Los productos son diversificados en las formas y volúmenes de las piezas y se diferencian en base a los tejidos estampados y las impresiones localizadas desarrolladas por los diseñadores de la compañía.

Las empresas de servicios de estampado de tela, de estampado localizado y de lavandería fueron visitadas.

La estamparía del tejido desarrolla máquinas de sellado del design creado por diseñadores de la empresa. Generalmente son tres cilindros con diferentes imágenes que generan seis combinaciones de estampados en tela roja "tinto" con el color liso. Hay un tiempo de espera para que las previsiones de las ventas por estimativas de los representantes se confirmen. La colección está a disposición de los representantes y solamente el número de artículos vendidos es destinado al proceso de producción.

La estrategia de Postponement en el teñido de prendas confeccionadas LT (Listo para Teñido) fue utilizada por la empresa en función de este producto en particular estar diseñado para responder a una gama muy específica de colores de moda. Sólo han sido enviados para ser teñidos las cantidades de piezas, conforme la numeración y el color de la piezas vendidas. Partes de los pantalones vaqueros también aguardan el resultado de las cantidades de los artículos vendidos. Sólo se envían al proceso de lavado las cantidades de los artículos vendidos por numeración y design de lavandería. 


\section{Conclusiones}

Se deduce la importancia del design que favorece la estrategia de Postponement en el proceso de Fabricación de la Ropa de Moda. La estrategia permite ganancias en el proceso de producción en masa, proporciona flexibilidad en las modificaciones del lote final y cumple eficazmente las necesidades del mercado.

Se constató que en la compañía investigada el uso de esta estrategia permitió la flexibilidad en el atendimiento de la demanda, tanto en relación a la cantidad de piezas, como a los tamaños y el estilo de los productos.

Al final fueron producidas piezas de acuerdo con las necesidades de los clientes y la flexibilidad de producción evitó la falta de piezas para los clientes finales.

La acción resultó en una reducción de las existencias de piezas acabadas. Algunas piezas quedaron en stock sólo debido a la cancelación de algunas ventas, una práctica común en este mercado.

El stock de materias primas se hizo más homogéneo. Lo que quedó después de la producción se tejió en LT (Listo para Teñido), pocos metros de tejido en cada estampa y color. La materia prima utilizada en los productos fue teñida y estampada lo más próximo posible a la necesidad del mercado.

\section{Referencias Bibliográficas}

Andreoni, M.A.D.L. (2008). Estamparia Têxtil: Uma estratégia de diferenciação do produto da Manufatura do Vestuário doe Moda. Dissertação (Mestrado em Engenharia de Produção) Universidade Paulista, São Paulo.

Araujo, M. de. (1996). Tecnologia do Vestuário. Lisboa: F. C. Gulbenkian.

Charoux, O.M.G. (2006). Metodologia: processo de produção, registro e relato do conhecimento. São Paulo: DVS.

Cunha, D.C. (2002). Avaliação dos Resultados da Aplicação de Postponement em uma Grande Malharia e Confeç̧ão de Santa Catarina Dissertação (Mestrado em Engenharia de Produção) Universidade Federal de Santa Catarina, Santa Catarina.

Clariant, Indústria química S.A. Catálogo, apresentação de tendências. Inverno 2007, 2006.

Denis, R. C. (1996). Uma introdução à história do design. São Paulo: Edgard Blücher.

Jones, S. J. (2005). Fashion Design: manual do estilista. São Paulo: Cosac Naify.

IFM, Institutut Francais de La Mode, Catálogo de formandos 2005.

La Redute it, Catalogo de vendas, primavera Milão Roubaix, 2010.

Lakatos, E. M., Marconi, M. de A. (2010). Fundamentos de metodologia científica. 7. ed. São Paulo: Atlas.

Lipovetsky, G. (1989). O Império do Efêmero: a moda e seu destino nas sociedades modernas, São Paulo: Schwarcz. 
Lima, F. D. M. (2008). Estratégias Adotadas para o Estabelecimento de Parcerias e Relacionamentos da Cadeia Jeanswear. Dissertação (Mestrado em Engenharia de Produção) Universidade Paulista, São Paulo.

Mendes, F. D. (2010). Um Estudo Comparativo entre as Manufaturas do Vestuário de Moda do Brasil e da Índia. Tese (Doutorado em Engenharia de Produção) Universidade Paulista, São Paulo.

Mendes, F. D., Sacomano, J. B. Fusco, J. P. A. (2010). Rede de empresas: A cadeia têxtil e as estratégias de manufatura na indústria brasileira do vestuário de moda. São Paulo: Arte\&Ciência.

Porter, M. E. (2009) Competição Edição revista e amplidaa. Rio de Janeiro, Campus.

(2004). Competição: Estratégias Competitivas Técnicas para análise de indústrias e da concorrência. 2. ed. 9a reimpressão Rio de Janeiro: Campus.

Santista, Indústria têxtil. Catálogos de produtos e tendência 2005.

Souza, G. de M. (1987). O Espírito das roupas: A moda no século dezenove. São Paulo: Schwarcz. Van Hoek, R. I. (1998). Postponed manufacturing in European Supply Chain: A triangular approach.(Nederlandse geografische studies/Netherlands geographical studies), Van Waarden. Yin, Robert K. (2008). Case Study Research: Design and Methods (Applied Social Research Methods), 4a. ed. USA: Sage Publications Inc.

\begin{abstract}
Summary: This research is the result of the work of the Research Group "Fashion of the textile chain," according to the record of the Directory CNPq Research Groups. The fashion product has specific features offered by design which gives, through creation, a style whose purpose is to satisfy the desire for a particular target audience. Today fashion can be considered democratic, since the consumer audience is the star in making decisions about what should be produced. Every season fashion has to present a wide variety of innovations in their shapes, colors, materials and textures, enabling brands producing fashion garments to reach different target audiences to meet the wishes of both the most daring and innovative and the more conservative. The fashion product has to meet a market demand that seeks highly diversified products and with a high level of differentiation. The Postponement is a term that defines the decision to postpone the final stages of the production process for several reasons. It can be used in FRM as a strategy to increase the rate of product differentiation, as determined by consumer demand fashion.
\end{abstract}

Keywords: clothing - diferentiation - fashion - Postponement - strategy - treatment.

Resumo: Esta pesquisa é o resultado do trabalho do Grupo de Pesquisa A moda da cadeia têxtil, segundo o registro do Diretório dos Grupos de Pesquisa CNPQ.

O produto de moda tem características específicas oferecidas pelo desenho que outorga, através da criação, um estilo cuia finalidade é satisfazer o desejo de um determinado público objetivo. Hoje a moda pode ser considerada democrática, já que o público consumidor é o protagonista na toma de decisões sobre o que deve ser produzido. 
Em cada temporada a moda tem que apresentar uma ampla variedade de novidades nas suas formas, cores, materiais e texturas, fazendo possível que as marcas que produzem prendas de moda cheguem a diferentes públicos objetivo para satisfazer os desejos dos mais ousados e inovadores, os que seguem a moda e os mais conservadores que consumem uma moda mais moderada.

$\mathrm{O}$ produto de moda tem que satisfazer uma demanda do mercado que procura produtos altamente diversificados e com um alto nível de diferenciação. É importante que ao final do processo de produção, poucas peças tenham a mesma aparência.

O postponement é um término que define a decisão de adiar as etapas finais do processo de produção por várias razões. Pode ser utilizado na FRM como uma estratégia para aumentar a taxa de diferenciação dos produtos, tal como determina a demanda do consumidor de moda.

Palavras chave: diferenciação - estratégia - moda - Postponement - roupa - tratamento. 